\title{
Dynamics of international integration of government securities' markets
}

\author{
Manmohan S. Kumar ${ }^{a}$, Tatsuyoshi Okimoto ${ }^{b, *}$ \\ ${ }^{a}$ International Monetary Fund, 700 19th Street, N.W., Washington, DC, USA \\ ${ }^{\mathrm{b}}$ Graduate School of International Corporate Strategy, Hitotsubashi University, Japan
}

\section{A R T I C L E I N F O}

\section{Article history:}

Received 16 October 2009

Accepted 18 July 2010

Available online 22 July 2010

\section{JEL classification:}

C32

E43

G15

Keywords:

Smooth transition model

Copula

Time-varying correlations

Financial integration

\begin{abstract}
A B S T R A C T
This paper investigates the dynamics of international government bond market integration in six of the G7 economies over two decades leading up to the global crisis. It examines whether such integration had been significant; the extent to which integration at the short and long end of the yield curve differed; the nature of such integration; and the extent of the decoupling of the long rates from short rates. These issues are investigated using the rigorous smooth-transition copula-GARCH model framework. The results show that integration at the long end of the yield curve had been increasing, had become pronounced, and was significantly greater than at the short end. Decoupling between the short and long end of the yield curve was notable, with important implications for the efficacy of monetary policy in the period before the crisis.
\end{abstract}

(c) 2010 Elsevier B.V. All rights reserved.

\section{Introduction}

A large number of explanations have been advanced to explain the global financial and economic crisis that began in the summer of 2007 and gathered pace in the aftermath of the Lehman collapse in September 2008. ${ }^{1}$ While factors relating to weakness and lapses in the financial sector regulatory and supervisory framework and inappropriate incentives for financial market participants have been often singled out as the most serious proximate elements, a number of observers have also emphasized underlying elements related to the availability of credit, the stance of monetary policy and a regime shift that appears to have occurred with regard to the impact of monetary policy on the term structure of interest rates. This paper focuses on the narrow issue of the decoupling of short-term policy rates from longer-term bond yields, and the evolution of sovereign bond market integration. This contributes to an understanding of the underlying causes of the crisis, but it is also of interest in its own right and has important implications for issues relating to the efficacy of monetary policy and portfolio diversification.

The paper can also be seen as part of the large and growing literature on financial globalization and the international integration

\footnotetext{
* Corresponding author. Tel.: +813 4212 3096; fax: +81342123020.

E-mail addresses: mkumar@imf.org (M.S. Kumar), tatsuyoshi.okimoto@gmail. com (T. Okimoto).

1 There is already a voluminous literature in this area: for a summary of the key factors, see for instance, IMF (2009).
}

of national financial markets (for the latest survey, see Kose et al., 2009). There have been a number of studies focusing on the integration of national equity markets, but a smaller, albeit increasing, number of papers examining integration of fixed income markets, particularly of government bond markets (see Laopodis, 2003; Beliu, 2005; Breger and Stovel, 2005; Kim et al., 2006; Clarida, 2007; Davies, 2007; Lamedica and Reno, 2007; Abad et al., 2010; Panchenko and $\mathrm{Wu}, 2009$ ). The latter set of studies generally focuses on integration at the long end of the yield curve, and has been primarily motivated by concerns about diversification benefits. Their broad conclusion is that government bond markets have become more integrated in recent years, but that there are still significant benefits to diversification.

This paper contributes to the latter literature by examining specific issues related to the process of bond market integration, in particular for the major industrial countries, and argues that it is richer and more complicated than most of the existing studies indicate. The reason why the process of integration may be more complex is in part due to the fact of increasing globalization itself, combined with financial market innovation. The ongoing structural changes in the world economy, including in the underlying economic and financial market conditions, raise this complexity further. For instance, following from a suggestion by a number of observers that the home bias in bonds (as well as equities) has diminished, ${ }^{2}$ it is not unreasonable to hypothesize that there may

\footnotetext{
2 See, for instance, Greenspan (2007).
} 
well be different degrees of integration at the short and long end of the government yield curve.

At the short end, the degree of integration is dictated by the fact that monetary policy still holds sway on short-term interest rates and returns. If the business cycles across countries are synchronous and also lead to some synchronicity for policy, returns at the short end may be expected to be highly correlated. Where business cycles diverge, so do such returns. It could still be the case that, abstracting from the state of the cycle, the degree of correlation over this segment has increased over time. But presumably divergent cyclical conditions would continue to matter.

More importantly, this may have little bearing on the correlations at the long end of the curve. If long bond yields are being driven by global investor preferences, global savings and investment, international risk appetite, etc., then despite the term structure considerations, there could be significant sustained divergences between returns at the short and long end. For instance, suppose cyclical conditions between the Euro area and the US diverge, and monetary policy in the former is being tightened while in the latter it is being eased (as was the case until well after the beginnings of the crisis in the summer of 2007). The returns at the short end would diverge, but this may have little or no impact on returns at the long end which may primarily be dictated by global savings-investment balance and capital flows. In this context, it is worth noting the assessment by Greenspan (2007), just before the crisis, that "in retrospect, global economic forces, which have been building for decades, appear to have gained effective control of the pricing of longer debt maturities. Simple correlations between short- and long-term interest rates in the US remain significant, but have been declining for over a half-century. Asset prices more generally are gradually being decoupled from short-term interest rates."

The goal of this paper is to investigate rigorously the dynamics of international government bond market integration in the largest G7 economies (excluding Japan for reasons noted below) over the last two decades and focus on a number of different aspects. In particular, the paper addresses the following questions for the twodecade period leading up to the onset of the crisis: (i) has sovereign bond market integration been increasing? (ii) to what extent did the integration at the short and long end differ? (iii) how did the integration evolve? (iv) did long-term rates decouple from shortterm rates?

The paper investigates these issues using the relatively novel but rigorous six-variate smooth-transition copula-GARCH (STCG) model. The smooth transition model per se gives us a convenient method to capture dominant long-run trends of correlations in bond yields. In addition, the copula framework allows us to model and estimate marginal and copula models separately, increasing tractability to estimate a model of the magnitude used in this paper. The smooth-transition copula-GARCH framework essentially enables us to analyze the dynamics of correlations in the bond markets in a highly flexible and tractable way.

We apply the STCG model to the short- and long-term yield for G6 countries, namely Canada (CA), France (FR), Germany (GE), Italy (IT), the UK, and the US. It is, however, unrealistic to estimate the model including 12 variables even if we use the copula approach. We therefore consider four subgroups based on the country and type of yields. Two groupings of countries are based on the recent studies by Doyle and Faust (2005) and Stock and Watson (2005). They analyze the international business cycle dynamics and argue the emergence of two groups, namely the English-speaking (ES) group including CA, the UK, and the US, and the Euro-zone (EZ) countries consisting of FR, GE, and IT. Thus, we estimate the sixvariate STCG model for the following four subgroups: (i) shortand long-term yields for the ES countries, (ii) short- and long-term yields for the EZ countries, (iii) short-term yields for G6 countries, and (iv) long-term yields for G6 countries. This allows a detailed investigation of the market integration dynamics of the yield curve for the G6 countries.

Our empirical results indicate a striking difference in the correlation dynamics between changes in the short- and long-term yield, and between the ES and EZ countries. For the ES countries, short-term rates are correlated only weakly in the period leading up to the crisis. The average correlation among these countries was about 0.16 in the early 1990s, and has shown no significant increase over the past nearly two decades for CA-UK and UK-US pairs. Although the correlation for the CA-US pair increased significantly, its magnitude is still relatively low compared to the correlations between long-term yields. On the other hand, the long-term rates were moderately correlated (with average correlation 0.52 ) at the beginning of the 1990s. Strikingly, the long-yield correlation increased significantly and almost linearly throughout the sample period for all country pairs. The average correlation reached 0.84 by 2007 , suggesting a very high degree of market integration in these countries' long yields.

For the Euro countries, the basic results are similar. Correlations between short-term yields for FR-IT and GE-IT pairs have been low over the entire sample period; even though for the FR-GE pair the correlation increases in the second subperiod (2001-2007) compared to the first (1994-2000), it remains surprisingly low. In a noticeable contrast, European long-term rates experienced a more striking increase in integration (from 1996 to 1998). The degree of integration between the short- and long-term yield curves varies noticeably: the average correlation among the European short-term rates was 0.20 in 1995 and 0.24 in 2007, while the corresponding values for long-term rates were 0.59 and 0.98 , respectively. This difference between the market integration in European short- and long-term bond markets is similar to that in the ES countries, but given the European Monetary Union (EMU), is surprising for the former set of countries.

Our analysis also indicates clear-cut results for decoupling between the short- and long-term yields for the UK, US, FR, and IT. In addition, we show that the correlation between the short- and long-term yields for GE has been very small for the entire sample period. A wide array of tests supports the robustness of the results.

The results suggest that the evolution of interest rates at the short end of the curve up to the onset of the crisis continued to reflect domestic monetary policy as well as domestic economic and financial market conditions, with limited spillovers, while at the long end of the curve, the importance of global conditions and global investor preferences had been paramount. This leads to some clear implications for the term structure of interest rates in the government securities' markets.

The remainder of the paper is organized as follows: Section 2 briefly discusses a range of economic and financial issues related to the convergence hypothesis, and summarizes the results of existing studies; Section 3 introduces the econometric model and the estimation strategy, while Section 4 provides the empirical results; Section 5 concludes.

\section{Financial market and economic issues in government securities' markets}

\subsection{Factors underlying convergence}

The factors underlying the convergence in bond yields (nominal and real) have received increasing attention in recent years. As Clarida (2007) argues succinctly, a key element had been a decline in "home bias," reducing the preference of investors for domestic bonds and leading to increased international diversification. This change in preferences in turn is considered to reflect a variety of 
factors: a reduction in hedging costs related to international diversification, and prior to the crisis, lower volatility in country-specific inflation and growth rates, reflecting in turn a convergence in the goals and implementation of monetary policy. ${ }^{3}$

Complementing these factors and perhaps accentuating them has been the role of other structural changes in the world economy and the role of common global shocks. For instance, there is growing evidence that the international trade integration of major emerging markets such as China and India, the accumulation of large foreign exchange reserves, and an increase in the global pool of savings might have had an impact on the convergence of bond yields. There are several different facets of this: higher trade integration and large current account surpluses (in emerging markets as well as oil-producing countries) increase the potential resources available for investment. These complement the "excess" savings in some of these economies reflecting in part the domestic economic and financial considerations as well as demographic factors. Given the small size of domestic financial markets in many of the countries with excess savings, the need for international investment and diversification of these assets is evident. This in turn would be expected to have downward pressure on bond yields in all major financial markets (see Hauner and Kumar, 2006). This would occur both directly as well as through arbitrage opportunities, especially given the fact that while the underlying fiscal sustainability positions in the different G7 countries could be regarded as being quite different (see, for instance, Hauner et al., 2007), the likelihood of debt servicing difficulties and outright default was considered to be remote in all countries. In other words, these underlying factors reflecting higher global savings and increased international diversification sustained the downward pressure on bond yields and in their convergence. Such a pressure is seen to be almost invariant to the stance of monetary policy in individual G7 countries. ${ }^{4}$

It should be noted that the above argument does not require the assumption of an increasing synchronicity of business cycles in the world. Rather, regardless of the state of the cycle, the level of output gap, the rate of inflation, as well as the associated response of monetary policy in individual countries, structural change would be expected to lead to a convergence in bond yields. A different type of structural change, but with somewhat similar consequences, refers to the formation of the EMU in 1999: in this case, a variety of other factors played a role, but the decline in the home bias was equally marked.

If it is the case that the synchronicity in the business cycle has not increased significantly, then the expectation would be that monetary policy stance could diverge quite substantially among the major industrial countries. This would then mean that shortterm interest rates-typically from overnight up to six-month T-bill rates-while exhibiting somewhat higher correlation, could nonetheless continue to diverge. This in turn suggests that the yield curves across the G7 countries are likely to continue to exhibit meaningful divergence, with the long end of the curve becoming ever more correlated and the short end reflecting a much weaker correlation.

A cursory glance at the data supports the above hypothesis. Table 1 reports the sample correlation coefficients between the shortand long-term yields across G7 countries for two subsamples. As can be seen, long-run yields are highly correlated with a marked increase in the comovement between the first and second subsample periods (1994-2000 and 2001-2007, respectively). At the same

\footnotetext{
${ }^{3}$ For evidence and analysis of the convergence in inflation rates in the G7 economies, see Kumar and Okimoto (2007).

4 The extent to which the impact of domestic monetary and fiscal stance may be superseded by this global shock is the subject of active research. For a discussion of the fiscal aspects of this, see Hauner and $\operatorname{Kumar}(2006,2009)$
}

time, however, correlations in the short-term interest rates generally remain at a much lower level. Note also that correlations between the short- and long-term yields typically become weaker in the latter subsample.

What would be the implications of this analysis for the benefits or otherwise of international diversifications, even among the G7 investors? As Clarida (2007) notes, even where there are differences in bond yields across countries, it does not imply differences in currency hedged bond returns since if countries with higher bond yields also have higher short-term interest rates, then the cost of hedging currency exposure in holding foreign bonds may offset the higher foreign yield. This would then suggest that a portfolio of foreign securities hedged back into dollar would produce similar total return as a dollar portfolio, with the two only diverging to the extent of home bias, and different degrees of risk aversion. But what if the bond yields are not significantly different but the short-term rates are? This would imply that cost of hedging may outweigh the foreign yield advantage, reducing the average hedged return to foreign bonds.

On the other hand, if (counterfactually) domestic country-specific risk is reduced because of lower business cycle risk, and the correlation in bond yields (while increasing) is lower, diversification may still be beneficial. Clarida's (2007) argument is that this would suggest that "a currency hedged, diversified portfolio of government bonds should produce similar average returns to a passively held US treasury portfolio, but with possibly lower volatility" (p. 3). He examines data on monthly total returns on US treasuries and foreign government bonds hedged back into dollars for two periods, 1990-1998 and 1999-2006, and finds that for the first period, the average realized excess returns of hedged foreign portfolio over US treasuries was around 40 basis points (9\% versus $8.6 \%$ a year respectively), with lower realized volatility of foreign portfolio (3.6\% versus $4.3 \%$ ). For the more recent period, the average excess returns to the foreign portfolio declined to just 10 basis points, but the volatility of the foreign portfolio was significantly lower than in the earlier period (in part due to EMU), suggesting that the gains to diversification have continued. He argues that since there continues to be a significant country-specific component to business cycles and bond returns, and there are differences in countries' monetary policy reaction functions, there will remain gains to international diversification.

With regard to underlying causes, it is the case that this convergence has been becoming more pronounced over a period that had seen a notable decline in real exchange rate volatility among the G7 economies. Consistent with the earlier study by Fidora et al. (2007), this suggests that a decline in home bias, attendant upon a reduction in exchange rate risk, may have played a role. However, as noted earlier there does not appear to be an increase in convergence in the business cycles or in the monetary policy stance. This in turn lends support to the hypothesis that the structural change in the world economy or a global shock may have played a role in the convergence process.

While there have been a number of studies that have explored directly the international integration of government bond markets (see references in the previous section, in particular Beliu, 2005; Breger and Stovel, 2005; Kim et al., 2006; Clarida, 2007; Davies, 2007), only a handful have focused on the largest and the most liquid of these markets, viz., those of the G7 economies. Also, most studies have assessed the level of integration at a given point in time; where they have looked at changes in the degree of integration, they have evaluated changes in it over two different time periods. Where a more continuous approach is used (Barr and Priestley, 2004), time-variation in the level of integration is rejected. This is one of the very few studies that examine the continuous evolution of the degree of integration of the government bond markets. Moreover, there are few studies that have tried to exam- 
Table 1

Correlations for the first and second subsamples.

\begin{tabular}{|c|c|c|c|c|c|c|c|}
\hline & \multirow[t]{2}{*}{ Sample period } & \multicolumn{3}{|c|}{ English-speaking group } & \multicolumn{3}{|c|}{ Euro-zone group } \\
\hline & & CA-UK & CA-US & US-UK & FR-GE & FR-IT & GE-IT \\
\hline \multirow[t]{2}{*}{ Short-term yields } & 1994-2000 & 0.086 & 0.284 & 0.137 & 0.122 & 0.324 & 0.145 \\
\hline & $2001-2007$ & 0.176 & 0.401 & 0.193 & 0.557 & 0.284 & 0.243 \\
\hline \multirow[t]{2}{*}{ Long-term yields } & $1994-2000$ & 0.545 & 0.814 & 0.632 & 0.925 & 0.684 & 0.591 \\
\hline & $2001-2007$ & 0.736 & 0.873 & 0.763 & 0.990 & 0.981 & 0.979 \\
\hline \multirow[t]{2}{*}{ Cross yields } & $1994-2000$ & 0.802 & 0.217 & 0.360 & 0.319 & 0.032 & 0.392 \\
\hline & $2001-2007$ & 0.767 & 0.166 & 0.227 & 0.194 & 0.069 & 0.057 \\
\hline
\end{tabular}

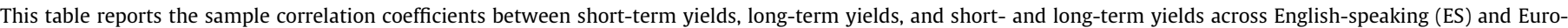
zone (EZ) countries for two subsamples.

ine the integration at both the short and long end of the yield curve. The application of the novel methodology to this issue has not been attempted before and shows that this is a particularly promising approach. The data are the most recent available, and we have paid special attention to the quality of the data. We have also taken into account the trade and financial linkages across countries that may be of special importance in assessing the bond market integration.

The objectives and conclusions of some of the main studies are as follows: Kim et al. (2006) examine the relationship between government bond (and stock) returns across a sample of countries to assess financial market integration. They show that there has been a downward trend in time-varying conditional correlations between bond (and stock market) returns in European countries, Japan, and the US. Their focus is on the impact of the monetary policy integration in Europe that is considered to have created uncertainties and led to a flight to quality.

In an earlier study, the Barr and Priestley (2004) model expected risks and returns on government bonds, allowing for a partial integration of national and world bond markets. Using a conditional asset pricing model that allows variation in the price of risk, they find strong evidence that national markets are only partially integrated into world markets: They find that around one quarter of total expected excess returns are related to local market risk, and the remainder being due to world bond market risk. However, they reject the hypothesis of time-variation in the level of integration. In a follow-up study, Lamedica and Reno (2007) extend Barr and Priestley's (2004) analysis to the EMU period. They find a higher level of integration in all countries except in Japan.

Davies (2007) uses MSCI bond index data to assess the degree of international bond market integration using cointegration techniques. Using daily data for the period 1994-2006, the analysis shows that bond markets are governed by a common long-run relation that is subject to periodic structural change. The analysis employs regime switching techniques to allow for structural change in the long-run equilibrium. By allowing for breaks in the long-run relation, the analysis provides evidence of international bond market integration.

\subsection{Convergence in bond yields in the Euro area}

There is significant evidence of a decline in home bias in financial markets in the countries of the Euro area even before the start of the EMU in 1999, and which accelerated over the subsequent period (see, for instance, Balli, 2009). As would be expected, there has also been a marked convergence in government bond yields starting in the mid-1990s, reflecting reduced transaction costs following the abolition of various restrictions on nonresidents, increased competition, and nominal convergence flowing from the Maastricht criteria for macroeconomic performance (specifically inflation and long-term rates). Relatedly, the constraints on general government deficit and debt-to-GDP ratios enshrined in the Stability and Growth Pact led to better fiscal balances and, following the start of the EMU, the introduction of the Euro, and the elimination of exchange rate risk, further improved transparency, reduced transaction costs, and facilitated the convergence of interest rates. ${ }^{5}$

However, Favero et al. (2010) show that despite the dramatic convergence in bond yields for both sovereign (and corporate) bonds in the transition to the EMU, the persistence of small and variable yield differentials for sovereign debt indicates that Euro area bonds are still not perfect substitutes. They regard this as reflecting not so much a continued market segmentation and even less so liquidity differences, but rather small differences in underlying risk. In a similar vein, utilizing later data and modeling the time varying nature of government bond market integration in the context of multivariate GARCH framework, Balli (2009) also suggests that the bond markets, while strongly converging, are not fully integrated with each other. ${ }^{6}$

Beliu (2005) investigates whether bond market returns of the US and five of the European Union countries-Austria, France, Germany, Netherlands and the UK-share the same volatility process. Using the common feature approach (a generalization of cointegration in the first moments), it is seen that the first four of the EU countries (members of the Euro area) do share the same volatility process, suggesting regional integration among the markets. However, there is little indication of a common volatility process between the UK and the other European markets, while there is evidence of this among the US and the UK markets. This methodology, however, while useful to illustrate the degree of convergence in the bond yields, is not able to isolate the period when there are marked changes in the degree of integration, nor how it has evolved over time.

\subsection{Home bias}

To the extent that the correlations have increased significantly, it raises issues regarding the benefits of international diversification, in terms of reducing the variance of the portfolio for a given rate of return. If that is the case, then the notion of portfolio "home

\footnotetext{
${ }^{5}$ There is significant literature in this area. See, for instance, European Commission (2001, 2003), Duisenberg (2002), Hardouvelis et al. (2006) and Favero et al. (2010). In particular, Hardouvelis et al. (2006) explores the impact of EMU on European stock integration by assessing the evolution of the relative influence of EU-wide risk factors over country specific risk factors on required rates of return. The empirical results show that in the second half of the 1990s, the degree of integration increased to the point where individual Euro-zone country stock markets appeared to be fully integrated into the EU market, with the evolution of inflation differential being a key element behind the level of integration. The exception was the UK which did not show any sign of increased stock market integration.

${ }^{6}$ While the situation in the Euro area is unique, movements toward development of regional wide sovereign and corporate debt have been occurring in other parts of the world also. For instance, ASEAN countries have been according domestic bond market development and promotion of a regional market a priority. See, for instance, Click and Plummer (2005)
} 
bias" as postulated by Poterba (1989) and Tesar and Werner (1995), which is considered to arise in part due to information asymmetries and other transaction and information costs, can be seen from a somewhat different perspective. It is the case that side-by-side with a decline in home bias, there appears to have been an increase in Euro area portfolio bias, whereby investors appear to hold a suboptimal proportion of financial assets originating from outside of the Euro area.

The factors underlying the home bias have been investigated at length (see, for instance, Ahearne et al., 2004; Fidora et al., 2007). These include the effect of transaction and information costs on international portfolio positions, the role of policies and the quality of domestic institutions, and to a lesser extent the role of exchange rate volatility. However, with regard to the latter, Fidora et al. (2007) show that real exchange rate volatility is an important determinant of cross-country differences in bilateral home biases in bonds as well as equities, and that bond home bias is more pronounced than equity home bias. The latter finding is seen to be consistent with the authors' hypothesis of "Markowitz-type international CAPM that financial assets with lower underlying volatility should exhibit a larger home bias." Their empirical analysis based on a large sample of industrial and emerging market countries suggests that a given reduction in real exchange rate volatility is likely to lead to a significant reduction in bond home bias that exceeds the reduction in equity home bias by a factor of $3 .^{7}$

In the case of the Euro area convergence of bond yields, it has been argued that the default risk of members going into EMU declined significantly reflecting the marked improvement in the countries fiscal positions and the budgetary policy framework more generally. The latter reflected in large part the need to abide by the Stability and Growth Pact. But the fact that there would be convergence does not say much about its extent or the speed with which it was attained. While bond yields among the "high risk" countries such as Italy had begun to converge in the run up to EMU and continued to do so afterwards, the mapping between the fiscal consolidation and convergence was far from isomorphic or monotonic. Rather, the decline in underwriting and transaction costs within the Euro area is likely to have played an important role. $^{8}$

Nonetheless, even with the increasing convergence in yields, the perceived creditworthiness of the member states shows a considerable amount of variation and, of course, changes over time. This in turn has meant that the convergence, while very strong, may not be perfect. ${ }^{9}$

\section{Econometric model and the estimation strategy}

To assess and analyze the dynamics of correlations in international government bond markets, we use the six-variate smoothtransition copula-GARCH (STCG) model. The smooth transition model per se can give us a convenient method to capture dominant long-run trends of correlations in bond yields. In addition, the copula framework allows us to model and estimate marginal and copula models separately, increasing tractability to estimate a model of the magnitude used in this paper. The smooth-transition cop-

\footnotetext{
${ }^{7}$ Specifically, for their sample of industrial and emerging market economies, the authors show that a reduction of the monthly real exchange rate volatility from its sample mean to zero reduces bond and equity home bias by around 60 and 20 percentage points, respectively.

${ }^{8}$ Lane (2006) finds that individual Euro area economies' international bond holdings are heavily weighted towards intra-Euro area holdings, and trade linkages and geographical proximity are seen to be key determinants of intra-Euro area bond holdings.

9 The argument here is analogous to the creditworthiness and the yield spreads for individual states in the United States, or among the Canadian provinces (see, for instance, Bayoumi and Eichengreen, 1998).
}

ula-GARCH model thus enables us to model the dynamics of correlations in the bond markets in a flexible and tractable way. This section describes the model for margins, copula, and dynamics of correlations successively, and then discusses the estimation strategy.

The methodology is novel. The only recent application we are aware of, which in part has a somewhat similar approach, is by Berben and Jansen (2005) in their analysis of the dependency between international equity markets when returns are reckoned to exhibit time-varying correlations. Their methodology is based on the bi-variate normal GARCH model with time-varying correlation described by a smooth transition model. Our model can be regarded as an extension of their model by adopting the copula approach, which allows us to use Student's t-distribution as a marginal. In addition, the copula framework can give us flexibility to estimate first the univariate distributions and then the copula function, with the dependency parameter rendered time-varying. As a consequence, our model can accommodate as many as six variables. See also Jondeau and Rockinger (2006), Patton (2006a), Okimoto (2008), Cai et al. (2009) and Yang et al. (2009), among others, for the recent studies analyzing time-varying dependence using the smooth transition model or copula theory.

\subsection{Marginal distributions}

According to the copula theory based on Sklar's (1959) theorem, the $n$-variate joint distribution function $H(\cdot)$ can be written as

$H\left(x_{1}, \ldots, x_{n} ; \boldsymbol{\theta}\right)=C\left(F_{1}\left(x_{1} ; \boldsymbol{\theta}_{1}\right), \ldots, F_{n}\left(x_{n} ; \boldsymbol{\theta}_{n}\right) ; \boldsymbol{\delta}\right)$.

Here $\boldsymbol{\delta}$ is a parameter vector for the copula, $\boldsymbol{\theta}_{1}, \ldots, \boldsymbol{\theta}_{n}$ are parameter vectors for each marginal distribution, and $\boldsymbol{\theta}=\left(\boldsymbol{\delta}^{\prime}, \boldsymbol{\theta}_{1}^{\prime}, \ldots, \boldsymbol{\theta}_{n}^{\prime}\right)^{\prime}$ is a parameter vector for the joint distribution. Thus, Eq. (1) indicates that the joint distribution can be decomposed into two parts: marginal distributions $F_{1}, \ldots, F_{n}$, describing the marginal behavior of each variable, and a copula $C$, representing the dependence structure among all variables. This decomposition allows us to model marginal distributions and dependence structure separately. In this subsection, we describe the model for marginal distributions, followed by the model for copula in the next subsection.

For the marginal distributions, we use the $\operatorname{AR}(4)-\operatorname{GARCH}(1,1)$ model with Student's $t$-disturbance. Specifically, the model for margins can be expressed as

$$
\left\{\begin{array}{l}
x_{i t}=c_{i}+\phi_{i 1} x_{i, t-1}+\phi_{i 2} x_{i, t-2}+\phi_{i 3} x_{i, t-3}+\phi_{i 4} x_{i, t-4}+\varepsilon_{i t}, \\
\varepsilon_{i t}=\sqrt{h_{i t}} u_{i t} \\
h_{i t}=\omega_{i}+\alpha_{i} \varepsilon_{i, t-1}^{2}+\beta_{i} h_{i, t-1}
\end{array}\right.
$$

for $t=1, \ldots, T$ and $i=1, \ldots, n$, where $T$ is a sample size and $n$ is a number of variables included in the model, namely six for this paper. We assume $u_{i t}$ follows Student's $t$-distribution with mean 0 , variance 1 , and the degree of freedom $v_{i}$. This specification is motivated by the well-known fact that the $\operatorname{GARCH}(1,1)$ model with Student's $t$-disturbance is able to capture many features of financial data, such as volatility clustering and fat-tailness. We also include AR terms in the conditional mean equation to treat a possible serial correlation of each variable.

Note that our copula framework allows each marginal model of Eq. (2) to have different degrees of freedom or fat-tailness. This is an important generalization, since the tail behavior of the government bonds in each international market could be different as we will confirm in the next section. As a result, each marginal model of Eq. (2) contains nine parameters; $\boldsymbol{\theta}_{i}=\left(c_{i}, \phi_{i 1}, \phi_{i 2}, \phi_{i 3}, \phi_{i 4}, \omega_{i}\right.$, $\left.\alpha_{i}, \beta_{i}, v_{i}\right)^{\prime}$. 


\subsection{Copula function}

For a copula, or a dependence structure, we simply use the normal copula, which is a copula for multivariate normal distribution and given as follows:

$C\left(u_{1}, \ldots, u_{n} ; \mathbf{R}\right)=\Phi_{\mathbf{R}}^{n}\left(\Phi^{-1}\left(u_{1}\right), \ldots, \Phi^{-1}\left(u_{n}\right)\right.$

Here $\Phi(\cdot)$ is a cumulative distribution function (CDF) of the standard normal distribution and $\Phi_{\mathbf{R}}^{n}(\cdot)$ is a CDF of the $n$-variate normal distribution with mean $\mathbf{0}$ and variance-covariance matrix $\mathbf{R}$. In our copula framework, $\mathbf{R}$ becomes a correlation matrix with unity along the diagonal elements, since variances are captured by the marginal model. This is relevant because a copula describes only dependence structures, not marginal behaviors. Note that we allow the correlation matrix $\mathbf{R}$ to be time dependent to describe the time-varying dependence. The model for the dynamics of correlations is discussed in detail in the next subsection.

We choose the normal copula for several reasons. First, the normal copula is easy to manipulate. As can be seen from the definition of the normal copula of Eq. (3), we need only the normal CDFs to calculate the normal copula. This tractability is essential to estimate large models such as the one in this paper. Second, the normal copula is flexible in the sense that it allows all possible pairs to have different correlations. This is important for our purpose, since we want to impose as few restrictions as possible on the dependence structures. To make this clear, let's consider an Archimedean copula as an alternative. ${ }^{10}$ The Archimedean copulas are more attractive than normal copula to describe asymmetric and extreme dependence, since the normal copula can capture only symmetric dependence with no tail dependence as emphasized by, among others, Embrechts et al. (2002). However, when it comes to the extension to more than three dimensions, the normal copula is superior to the Archimedean copulas. Although the multi-variate Archimedean copulas can be easily obtained, they typically have only one or two parameters. In other words, using the multivariate Archimedean copulas, we have to assume that correlations between all possible pairs are characterized by only one or two parameters, which is most likely a misleading characterization of the correlation structure in government bond markets. Lastly, even if we use the normal copula, our model can accommodate fat-tailness, since we employ the GARCH model with Student's $t$-disturbance for marginal models. Therefore, our normal copula model is not as restrictive as the multivariate normal distribution model employed by the most of previous studies in the multivariate framework.

\subsection{Dynamics of correlations}

To examine the evolution of bond market integration, we need to specify a model for the dynamics of correlations. To this end, we adopt the smooth transition model established by Teräsvirta (1994) in an autoregressive model framework. With the smoothtransition framework we can model the copula parameters, or the correlation matrix as

$\mathbf{R}_{t}=\left(1-G_{t}\right) \mathbf{R}_{1}+G_{t} \mathbf{R}_{2}$.

In other words, we assume that there are two correlation regimes and the regime transition is governed by a transition function, $G_{t}$. The transition function is often modeled by the logistic function as

$G_{t}=G\left(\xi_{t} ; \gamma, c\right)=\frac{1}{1+\exp \left(-\gamma\left(\xi_{t}-c\right)\right)}, \quad \gamma>0$,

where $\xi_{t}$ is a transition variable, and $\gamma$ and $c$ are smoothness and location parameters, respectively. Note that since the transition

\footnotetext{
${ }^{10}$ See Joe (1997) and Nelsen (2006) for details on the Archimedean copulas.
}

function $G_{t}$ takes values between 0 and 1 , as long as $\mathbf{R}_{1}$ and $\mathbf{R}_{2}$ are correlation matrices, $\mathbf{R}_{t}$ will be a correlation matrix as well.

For a transition variable, following Lin and Teräsvirta (1994) and Berben and Jansen (2005), we use a linear time trend, specifically, we set $\xi_{t}=t / T$. In addition, we assume $0.15 \leqslant c \leqslant 0.85$ so that we can detect the correlation transition within sample period. By doing so, we can capture dominant long-run trends of international government bond market integration, since the correlation matrix of the international bond markets changes from $\mathbf{R}_{1}$ to $\mathbf{R}_{2}$ monotonically with time. In addition, we can test the changes in a correlation for a specific pair by testing the difference between the corresponding elements of $\mathbf{R}_{1}$ and $\mathbf{R}_{2}$. For example, if we want to test the changes in correlation between government bond yields 1 and 2 , we can test the difference between the $(1,2)$ elements of $\mathbf{R}_{1}$ and $\mathbf{R}_{2}$. More specifically, we can test the null hypothesis $H_{0}: r_{12}^{1}=r_{12}^{2}$ against the alternative hypothesis $H_{1}: r_{12}^{1} \neq r_{12}^{2}$, where $r_{i j}^{k}$ is the $(i, j)$ element of $\mathbf{R}_{k}$.

Another attractive feature of the smooth transition models is that they can allow data to choose the pattern of transition. The change is abrupt for large values of $\gamma$, while the transition is gradual for small values of $\gamma$. Furthermore, the location parameter $c$ can adjust the location of the reflection point. Thus, the smooth transition model can describe a wide variety of patterns of change and select empirically the best pattern for the international bond market data, which is particularly attractive for our purpose.

Note that each correlation matrix has $n(n-1) / 2$ parameters and the transition function has two parameters. Thus, our copula specification of Eqs. (3)-(5) contains $n(n-1)+2$ parameters to estimate. Specifically, $\boldsymbol{\delta}=\left(c, \gamma, \overline{v e c h}\left(\mathbf{R}_{1}\right)^{\prime}, \overline{v e c h}\left(\mathbf{R}_{2}\right)^{\prime}\right)^{\prime}$, where $\overline{v e c h}(\mathbf{A})$ is defined as a column vector consisting of the elements of $\mathbf{A}$ below diagonal.

\subsection{Estimation strategy}

Since we have fully specified the model, we can derive the (conditional) log-likelihood function $l(\boldsymbol{\theta})$ to implement the maximum likelihood estimation (MLE). In a copula framework, we differentiate the joint distribution (1) with respect to $x_{1}, \ldots, x_{n}$ to get the joint density of $x_{1}, \ldots, x_{n}$ as

$$
\begin{aligned}
\frac{\partial H\left(x_{1}, \ldots, x_{n} ; \boldsymbol{\theta}\right)}{\partial x_{1} \cdots \partial x_{n}}= & c\left(F_{1}\left(x_{1} ; \boldsymbol{\theta}_{1}\right), \ldots, F_{n}\left(x_{n} ; \boldsymbol{\theta}_{n}\right) ; \boldsymbol{\delta}\right) \times f_{1}\left(x_{1} ; \boldsymbol{\theta}_{1}\right) \\
& \times \cdots \times f_{n}\left(x_{n} ; \boldsymbol{\theta}_{n}\right) .
\end{aligned}
$$

Here $c(\cdot)$ is a density function of copula defined as

$c\left(u_{1}, \ldots, u_{n} ; \boldsymbol{\delta}\right)=\frac{\partial C\left(u_{1}, \ldots, u_{n} ; \boldsymbol{\delta}\right)}{\partial u_{1} \cdots \partial u_{n}}$,

and $f_{1}, \ldots, f_{n}$ are density functions of each marginal. Thus, the loglikelihood function $l(\boldsymbol{\theta})$ can be obtained from Eq. (6) as

$l(\boldsymbol{\theta})=\sum_{t=1}^{T} \ln c\left(F_{1}\left(x_{1 t} ; \boldsymbol{\theta}_{1}\right), \ldots, F_{n}\left(x_{n t} ; \boldsymbol{\theta}_{n}\right) ; \boldsymbol{\delta}\right)+\sum_{i=1}^{n} \sum_{t=1}^{T} \ln f_{i}\left(x_{i t} ; \boldsymbol{\theta}_{i}\right)$.

In our specification, the copula density $c$ of Eq. (7) can be represented as

$c\left(u_{1}, \ldots, u_{n} ; \mathbf{R}_{t}\right)=\phi_{\mathbf{R}_{t}}^{n}\left(u_{1}, \ldots, u_{n}\right) \times \phi^{-1}\left(u_{1}\right) \times \cdots \times \phi^{-1}\left(u_{n}\right)$,

where $\phi_{\mathbf{R}}^{n}$ is a density function of $n$-variate normal distribution with mean $\mathbf{0}$ and variance-covariance matrix $\mathbf{R}$, and $\phi$ is a density of the standard normal distribution. Also, $f_{i}$ is given by the Student's $t$-density with mean $c_{i}+\phi_{i 1} x_{i, t-1}+\phi_{i 2} x_{i, t-2}+\phi_{i 3} x_{i, t-3}+\phi_{i 4} x_{i, t-4}$, variance $h_{i t}$, and the degree of freedom $v_{i}$.

Since the normal and Student's t-density functions are well known and available in most statistical packages, we can evaluate the value of $l(\boldsymbol{\theta})$ readily using Eqs. (8) and (9). However, we often 
encounter the difficulty in maximizing $l(\theta)$ with respect to a large number of parameters. Note that $\boldsymbol{\theta}$ consists of all parameters for copula and marginal distributions and contains $9 n+n(n-1)+2$ parameters. Thus, our six-variate smooth-transition copula-GARCH model has 86 parameters to estimate, meaning that it is formidable, if not impossible, to calculate MLE in practice. To overcome this difficulty, we employ a multistage maximum likelihood estimator (MSMLE) analyzed by Patton (2006b). The MSMLE is obtained by getting the MLE for the parameters for marginal distributions and copula separately. More precisely, to get the MSMLE, we first calculate the MLE for each marginal model by maximizing each marginal likelihood separately. Then we substitute those parameter estimates into the joint likelihood and calculate the MLE for copula parameters using this quasi-likelihood. Patton (2006b) shows that the MSMLE is asymptotically normal and as efficient as the true MLE under some regularity conditions.

Another advantage of the MSMLE is that we can use all available data rather than the overlapping data. As discussed in the next section, the availability of our data differs from country to country. Therefore, if we use the usual MLE, we have to make each sample size even by discarding a portion of samples other than overlapping data. Using the MSMLE, we can use all available data, which may increase the accuracy of parameter estimates for marginal distributions.

One concern using the MSMLE is to evaluate the standard errors of the MSMLE. Patton (2006b) provides the robust consistent estimator for the asymptotic variance-covariance matrix of the MSMLE for the bi-variate case. Theoretically, it can be easily extended to the multivariate case and used to evaluate standard errors, but in practice it is a formidable task to calculate it accurately, in particular, when the number of parameters is large. For this reason, we use the usual standard errors obtained in each stage of calculating the MSMLE as the approximate standard errors for the MSMLE. This is innocuous for marginal distribution parameters, but not for copula parameters, since we treat parameter estimates for the marginal distributions as given when estimating copula parameters. However, it should not be a serious problem, if sample size is large, which is so in this paper. ${ }^{11}$

\section{Empirical analysis}

\subsection{Data}

The data are initially obtained for daily bond yields adjusted for maturity (obtained from Bloomberg and IMF). Daily data are seen to be desirable to increase the information available for testing the underlying hypotheses. However, as a number of other studies have indicated, serious issues are raised by the differential timezone effects, with trading hours for markets in North America and Europe overlapping only partially. Indeed, as Martens and Poon (2001) show, lack of common trading hours and the resultant asynchronous data can lead to a significant downward bias in estimates of correlations. Given this, the data on daily yields are averaged into weekly data, and the bulk of the analysis is undertaken using these weekly averages.

The weekly averages are computed for both short- and longterm government bond yields for G7 countries except Japan (Canada (CA), France (FR), Germany (GE), Italy (IT), UK, and US). We exclude Japan from our analysis, since the unique Japanese low growth and deflation in the Japanese "lost decade" significantly distort the analysis. We use the three-month rate as the short-term rate and the ten-year rate as the long-term rate (the only exception is the Canadian short-term rate, proxied by the two-year rate since

\footnotetext{
11 Our shortest sample size is 690 for Italian three-month rates.
}

three-month and six-month rates are not available). The sample period is from January 1990 to November 2007, with the exception of the following; for the UK, the short rate is available from November 1992, while the short-yield data for GE can be used only from May 1993. In addition, the short- and long-term yields for IT are available from September 1994 and May 1993, respectively. We use the longest sample period in each of the exercises.

We take first differences in the short- and long-term rates of the yield curve to make the series stationary. In addition, changes are more appropriate to use, since we are interested in commensurate movements of monetary policy and global investor preferences, which are reflected by the change of interest rates, rather than the level itself (we do not pursue the issue of cointegration in this paper).

We classify 12 variables (short- and long-term government bond yields rates for G6 countries) into four six-variable groups in order to investigate the dynamics of correlations. This is so for two reasons: first, if all variables are included in one analysis, it is almost impossible to obtain reasonable estimates due to the large number of parameters. Second, in our STCG model analysis, we assume that all variables share the same transition function. We can make this assumption more reasonable by grouping variables with similar characteristics. For the country grouping, we refer to the results of Doyle and Faust (2005) and Stock and Watson (2005), which indicate the emergence of two groups, one consisting of English-speaking (ES) countries and the other of Euro-zone (EZ) countries. We, therefore, consider the following two groups based on countries. The first group corresponds to the ES countries and includes the short- and long-term government bond yields for CA, UK, and US. The second group consists of the short- and longterm government bond yields for EZ countries, namely FR, GE, and IT. In addition, we consider two more groups depending on the type of yield: the third group contains short-term yields for G6 countries, while the fourth group is for long-term yield groups.

Based on these four groups, we examine the evolutions of international government bond market integration from several aspects. For instance, the short end of the yield curve mainly reflects the stance of monetary policy, while the long bond yields are in addition driven by global investors' preference. As discussed earlier, it is very unlikely that the correlation dynamics in the two cases are similar. In particular, the analysis addresses the following questions: (i) has sovereign bond market integration been increasing? (ii) to what extent did the integration at the short and long end differ? (iii) how did the integration evolve? (iv) did long-term rates decouple from short-term rates?

In what follows, we first document the results of marginal models for all countries then report the results of each group's correlation dynamics for the short- and long-term rates.

\subsection{Results of the marginal model}

In this subsection, we document the estimation results of marginal model. We fit the AR(4)-GARCH( 1,1$)$ model with Student's $t$ disturbance of Eq. (2) to the short- and long-term government bond yields for each country. ${ }^{12}$ The estimation results indicate that AR parameters are jointly significant for all cases, meaning that both short- and long-term yields are significantly serially correlated. In addition, all results suggest that the GARCH effects are highly statistically significant. Furthermore, estimates of the degree of freedom are very small for most of the cases, indicating the fat-tailness of the disturbance. ${ }^{13}$ In particular, for the short-term rates, the degree

\footnotetext{
12 To save space, all parameter estimates are not reported, but are available from the authors upon request.

${ }^{13}$ We assume the degree of freedom $v$ is larger than 4 , or the existence of at least fourth order moment to guarantee the asymptotic normality of MLE. If this restriction is bound, we re-estimate the model with setting $v=4$.
} 
Table 2

Results of diagnostic tests for the marginal model.

\begin{tabular}{|c|c|c|c|c|c|c|c|c|}
\hline & & \multirow[t]{2}{*}{ Lag } & \multicolumn{3}{|c|}{ Standardized residual } & \multicolumn{3}{|c|}{ Squared standardized residual } \\
\hline & & & 5 & 10 & 20 & 5 & 10 & 20 \\
\hline \multirow[t]{12}{*}{ Short-term yields } & CA & Q-stat & 1.91 & 8.59 & 30.14 & 3.25 & 17.13 & 26.17 \\
\hline & & $p$-value & 0.862 & 0.571 & 0.068 & 0.662 & 0.072 & 0.160 \\
\hline & UK & Q-stat & 3.62 & 7.58 & 25.93 & 0.93 & 1.60 & 16.72 \\
\hline & & $p$-value & 0.606 & 0.670 & 0.168 & 0.968 & 0.999 & 0.671 \\
\hline & US & Q-stat & 4.71 & 10.39 & 54.97 & 5.81 & 7.99 & 13.40 \\
\hline & & $p$-value & 0.452 & 0.407 & 0.000 & 0.325 & 0.630 & 0.859 \\
\hline & FR & Q-stat & 9.80 & 14.63 & 43.01 & 1.18 & 4.01 & 18.61 \\
\hline & & $p$-value & 0.081 & 0.146 & 0.002 & 0.946 & 0.947 & 0.547 \\
\hline & GE & Q-stat & 0.95 & 3.08 & 32.97 & 7.61 & 23.30 & 33.36 \\
\hline & & $p$-value & 0.330 & 0.798 & 0.007 & 0.006 & 0.001 & 0.007 \\
\hline & IT & Q-stat & 4.32 & 13.44 & 27.44 & 2.26 & 17.83 & 27.41 \\
\hline & & $p$-value & 0.504 & 0.200 & 0.123 & 0.813 & 0.058 & 0.124 \\
\hline \multirow[t]{12}{*}{ Long-term yields } & $\mathrm{CA}$ & Q-stat & 3.71 & 5.53 & 18.46 & 9.24 & 10.38 & 24.35 \\
\hline & & $p$-value & 0.592 & 0.853 & 0.557 & 0.100 & 0.408 & 0.227 \\
\hline & UK & Q-stat & 2.93 & 9.97 & 15.97 & 2.11 & 3.24 & 18.98 \\
\hline & & $p$-value & 0.710 & 0.443 & 0.718 & 0.834 & 0.975 & 0.523 \\
\hline & US & Q-stat & 0.45 & 2.32 & 17.47 & 13.58 & 14.75 & 23.61 \\
\hline & & $p$-value & 0.994 & 0.993 & 0.622 & 0.019 & 0.141 & 0.260 \\
\hline & FR & Q-stat & 1.53 & 7.68 & 20.47 & 3.12 & 10.26 & 19.41 \\
\hline & & $p$-value & 0.910 & 0.660 & 0.429 & 0.682 & 0.418 & 0.495 \\
\hline & GE & Q-stat & 2.68 & 7.98 & 21.38 & 8.70 & 10.98 & 23.97 \\
\hline & & $p$-value & 0.749 & 0.631 & 0.375 & 0.122 & 0.359 & 0.244 \\
\hline & IT & Q-stat & 1.26 & 5.99 & 13.43 & 8.01 & 8.94 & 16.11 \\
\hline & & $p$-value & 0.939 & 0.816 & 0.858 & 0.156 & 0.538 & 0.710 \\
\hline
\end{tabular}

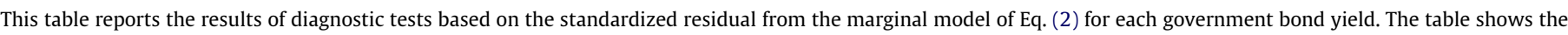

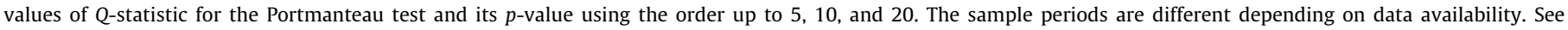
Section 4.1 for the available sample period of each series.

of freedom is estimated at less than 5 for all countries except CA, whose estimate is 7.2. The long-term rate results are not as striking as those of short-term rates, but still suggest a much fatter distribution than normal distribution with about 6-10 degree of freedom estimates for most of the countries. The highest degree of freedom is for the US with about 25, which is still fatter than normal. These results clearly demonstrate the importance of capturing the fat-tailness, hence the superiority of our copula-GARCH approach to the usual multivariate normal GARCH model.

Table 2 reports the results of diagnostic tests based on the standardized residual from the marginal model for each government bond yield. Specifically, we test the serial correlation in the standardized residuals and squared standardized residuals based on the Lyung-Box's Portmanteau tests. If marginal models are correctly specified, the standardized residuals are iid, implying no serial correlation in either original or squared series. The table shows the values of $Q$-statistic for the Portmanteau test and its $p$-value using the order up to 5,10 , and 20: most of the results indicate no significant serial correlation with $p$-values greater than 0.05 ; in particular, none of them are statistically significant at the $5 \%$ level for the long-term yields. Although short-term yields of the US, FR, and GE show some significant serial correlation in the longer horizon, it is extremely difficult to take care of these serial correlations in a parsimonious way. Overall, the results are acceptable, meaning that our models are satisfactory to describe the marginal behavior of the short- and long-term government bond yields.

\subsection{Results of the joint model}

In this subsection, we present the estimation results of the STCG models, specifically correlation dynamics for government bond yields, to answer the questions noted above. As explained in the

Table 3

Hypothesis tests of equivalence for correlations within each group.

\begin{tabular}{|c|c|c|c|c|c|c|c|c|}
\hline & & & \multicolumn{3}{|c|}{ English-speaking group } & \multicolumn{3}{|c|}{ Euro-zone group } \\
\hline & & & CA-UK & CA-US & UK-US & FR-GE & FR-IT & GE-IT \\
\hline \multirow[t]{6}{*}{ Short-term yields } & Regime 1 & Estimate & 0.036 & 0.181 & 0.106 & 0.150 & 0.267 & 0.182 \\
\hline & & Std. error & 0.083 & 0.081 & 0.090 & 0.068 & 0.066 & 0.066 \\
\hline & Regime 2 & Estimate & 0.143 & 0.445 & 0.111 & 0.322 & 0.228 & 0.167 \\
\hline & & Std. error & 0.055 & 0.055 & 0.057 & 0.038 & 0.042 & 0.043 \\
\hline & & Wald stat & 0.804 & 6.116 & 0.001 & 4.15 & 0.220 & 0.035 \\
\hline & & $p$-value & 0.370 & 0.013 & 0.971 & 0.042 & 0.639 & 0.852 \\
\hline \multirow[t]{6}{*}{ Long-term yields } & Regime 1 & Estimate & 0.051 & 0.604 & 0.099 & 0.859 & 0.500 & 0.398 \\
\hline & & Std. error & 0.174 & 0.070 & 0.171 & 0.014 & 0.065 & 0.072 \\
\hline & Regime 2 & Estimate & 0.893 & 0.938 & 0.922 & 0.988 & 0.978 & 0.976 \\
\hline & & Std. error & 0.100 & 0.043 & 0.098 & 0.001 & 0.002 & 0.002 \\
\hline & & Wald stat & 23.46 & 19.70 & 23.30 & 83.96 & 54.11 & 64.53 \\
\hline & & $p$-value & 0.000 & 0.000 & 0.000 & 0.000 & 0.000 & 0.000 \\
\hline
\end{tabular}

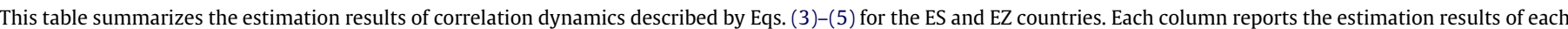

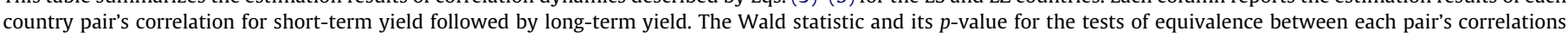

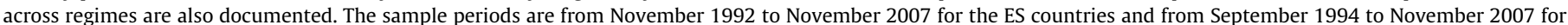
the EZ countries. 

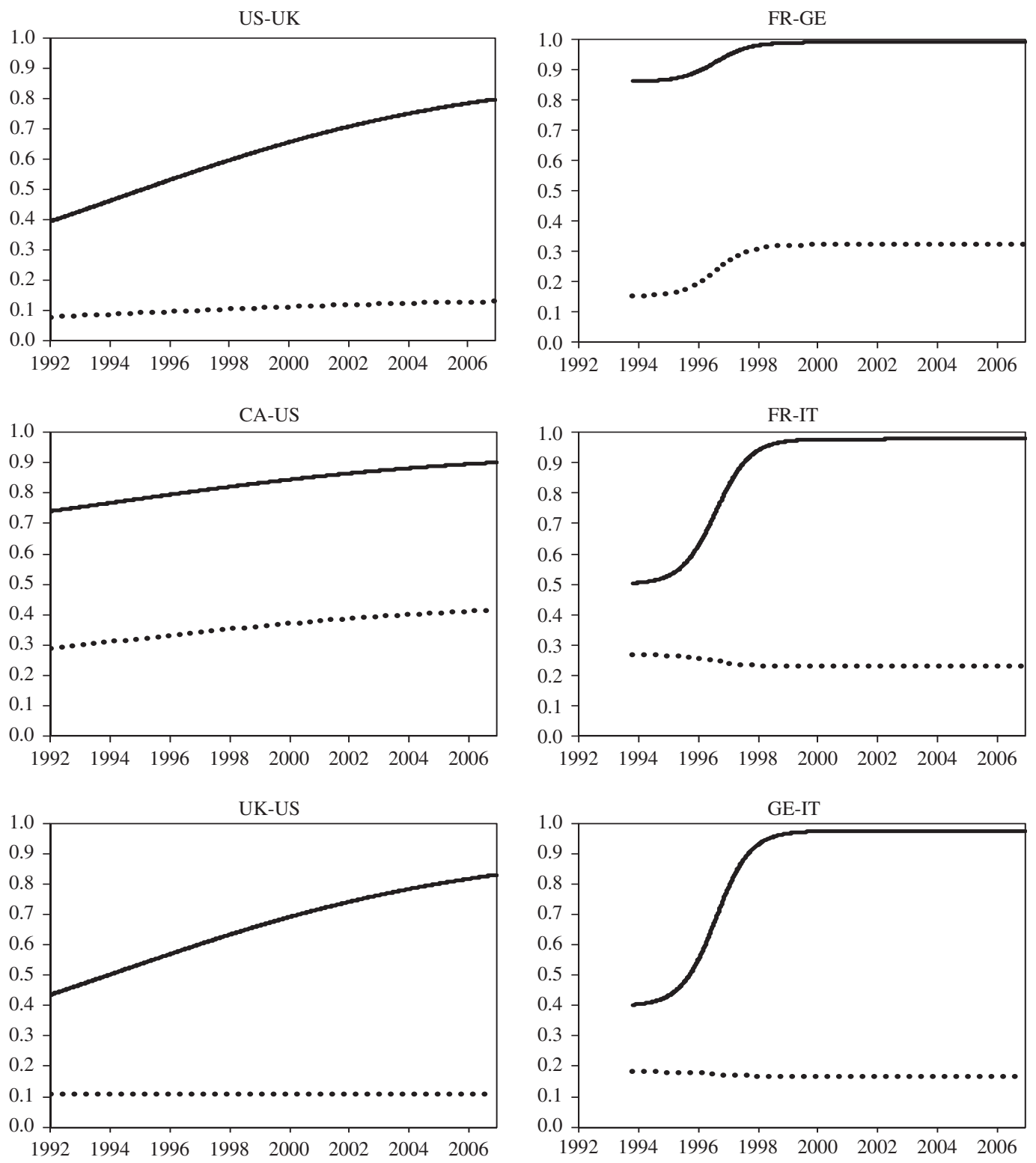

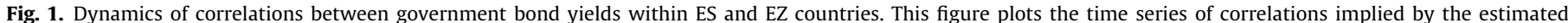

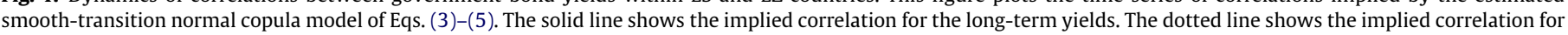
the short-term yields.

previous section, we employ the MSMLE to estimate parameters for smooth-transition normal copula model, meaning that we use the estimation results of the marginal model as given to estimate the joint model. We estimate the six-variate STCG model for four groups: (i) the short- and long-term government bond yields for ES countries, (ii) the short- and long-term government bond yields for EZ countries, (iii) the short-term yields for G6 countries, and (iv) the long-term yields for G6 countries.

The estimation results for the ES country group based on the sample from November 1992 to November 2007 are summarized in Table 3 . There are three country pairs in the group, namely CA-UK, CA-US, and UK-US. Each column of the fourth to sixth column in this table reports the estimation results of each pair's correlation, showing the results for short-term yield followed by the long-term yield. In addition, the results of hypothesis tests for equivalence between each pair's correlations across regimes are documented. For example, correlations of CA-UK pair for the short-term yields are estimated at 0.036 and 0.143 with standard errors of 0.083 and 0.055 for regimes 1 and 2, respectively. The null hypothesis of equivalence between these two correlations is not rejected with $p$-value 0.370 . Recall that the correlation changes monotonically from $\rho_{1}$ to $\rho_{2}$ in our smooth-transition framework, where $\rho_{i}$ is correlation in the regime $i$. Thus, our results indicate no significant increase in the CA-UK correlation between short-term government bond yields over the sample period. As for the longterm yields, correlations are estimated at 0.051 with standard error 0.174 for regime 1 and at 0.893 with standard error 0.100 for regime 2 . The difference in correlations across regimes is highly statistically significant with essentially zero $p$-value. This is also true for the other two pairs. Both pairs' correlations for the long-term yields have increased remarkably in regime 2 to around 0.9 , while correlations for the short-term yields remain relatively low even for the CA-US pair, whose correlation for the short-term yield shows a marked increase from 0.181 to 0.445 .

To highlight the correlation dynamics visually, Fig. 1 plots the time series of correlations implied by the estimated smooth-tran- 
Table 4

Hypothesis tests of equivalence for correlations between short- and long-term yields.

\begin{tabular}{|c|c|c|c|c|c|c|c|c|}
\hline & & & \multicolumn{3}{|c|}{ English-speaking group } & \multicolumn{3}{|c|}{ Euro-zone group } \\
\hline & & & CA & UK & US & FR & GE & IT \\
\hline \multirow[t]{6}{*}{ Cross yields } & Regime 1 & Estimate & 0.787 & 0.353 & 0.665 & 0.553 & 0.068 & 0.442 \\
\hline & & Std. error & 0.021 & 0.091 & 0.123 & 0.047 & 0.080 & 0.065 \\
\hline & Regime 2 & Estimate & 0.798 & 0.101 & 0.246 & 0.217 & 0.084 & 0.076 \\
\hline & & Std. error & 0.016 & 0.063 & 0.089 & 0.042 & 0.044 & 0.045 \\
\hline & & Wald stat & 0.125 & 4.315 & 5.942 & 26.842 & 0.026 & 19.057 \\
\hline & & $p$-value & 0.724 & 0.038 & 0.015 & 0.000 & 0.872 & 0.000 \\
\hline
\end{tabular}

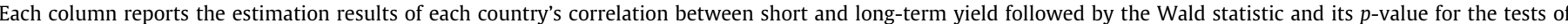

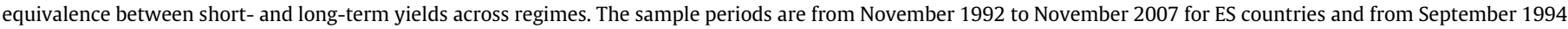
to November 2007 for EZ countries.

sition normal copula model. As can be seen from the figure, there are noticeable differences in correlation dynamics between the short-term yields (dotted line) and long-term yields (solid line). First, the degree of integration measured by correlation is much higher for the long-term than for the short-term yields. Average correlations for these ES country pairs over the sample period are 0.193 and 0.707 for the short and long yields, respectively. Second, correlations for the long yields are increasing almost linearly for all
CA

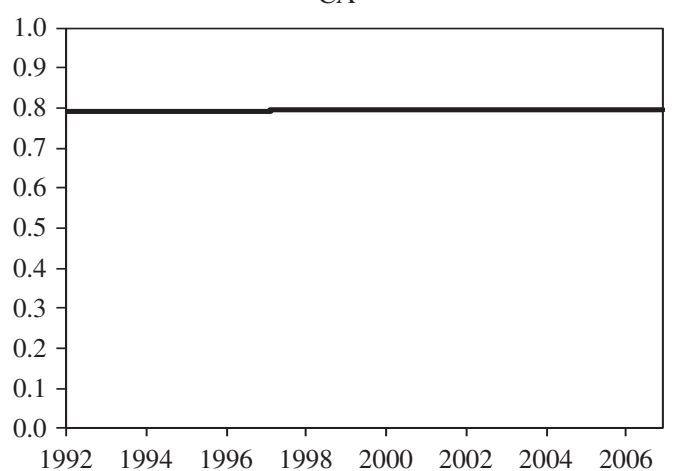

UK

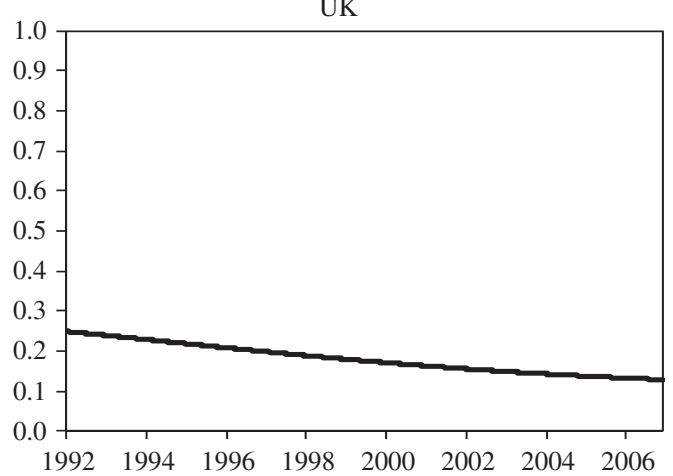

US

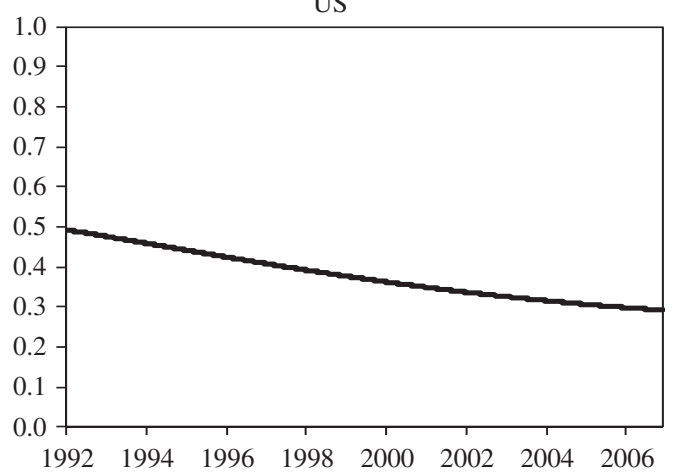

FR

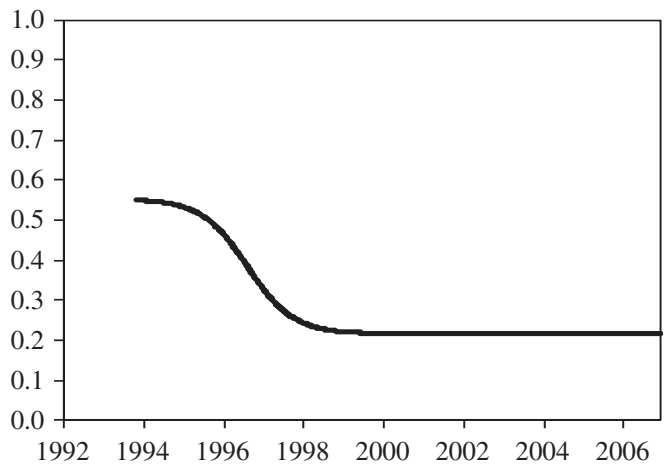

GE

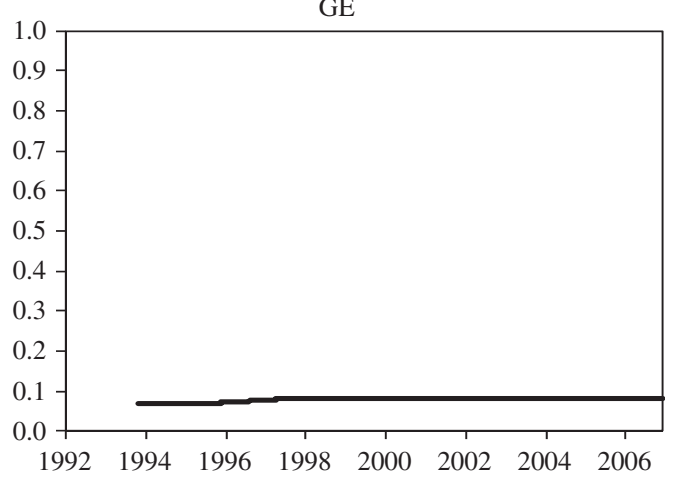

IT

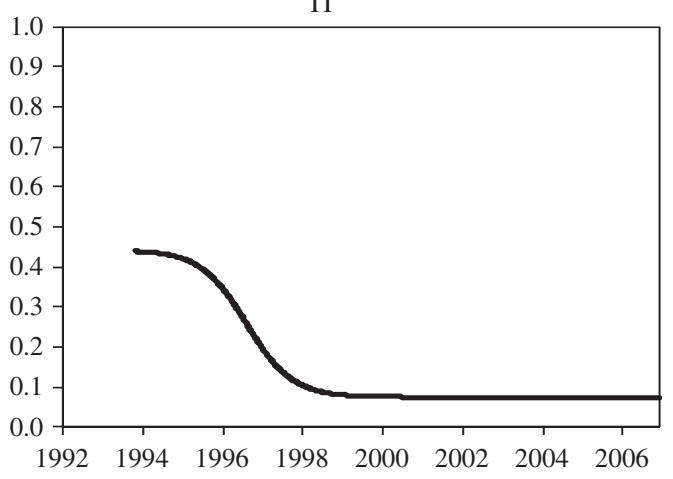

Fig. 2. Dynamics of correlations between short- and long-term government bond yields. This figure depicts the correlation dynamics between the short- and long-term yields implied by the estimated smooth-transition normal copula model of Eqs. (3)-(5). 
Table 5

Hypothesis tests of equivalence for correlations across the groups.

\begin{tabular}{|c|c|c|c|c|c|c|c|c|c|c|c|}
\hline & & & CA-FR & CA-GE & CA-IT & UK-FR & UK-GE & UK-IT & US-FR & US-GE & US-IT \\
\hline \multirow[t]{6}{*}{ Short-term yields } & Regime 1 & Estimate & 0.121 & 0.098 & 0.079 & 0.113 & 0.116 & -0.035 & 0.099 & 0.049 & 0.033 \\
\hline & & Std. error & 0.053 & 0.056 & 0.051 & 0.048 & 0.046 & 0.047 & 0.052 & 0.052 & 0.050 \\
\hline & Regime 2 & Estimate & 0.243 & 0.177 & 0.132 & 0.127 & 0.161 & 0.057 & 0.266 & 0.085 & 0.136 \\
\hline & & Std. error & 0.048 & 0.051 & 0.053 & 0.045 & 0.044 & 0.046 & 0.044 & 0.054 & 0.052 \\
\hline & & Wald stat & 2.821 & 0.996 & 0.496 & 0.035 & 0.475 & 1.805 & 5.623 & 0.213 & 1.863 \\
\hline & & $p$-value & 0.093 & 0.318 & 0.482 & 0.852 & 0.491 & 0.179 & 0.018 & 0.644 & 0.172 \\
\hline \multirow[t]{6}{*}{ Long-term yields } & Regime 1 & Estimate & 0.371 & 0.405 & 0.216 & 0.674 & 0.671 & 0.381 & 0.406 & 0.448 & 0.103 \\
\hline & & Std. error & 0.058 & 0.056 & 0.070 & 0.034 & 0.035 & 0.056 & 0.054 & 0.054 & 0.075 \\
\hline & Regime 2 & Estimate & 0.741 & 0.744 & 0.726 & 0.871 & 0.869 & 0.860 & 0.784 & 0.791 & 0.767 \\
\hline & & Std. error & 0.016 & 0.016 & 0.016 & 0.009 & 0.009 & 0.010 & 0.014 & 0.013 & 0.014 \\
\hline & & Wald stat & 34.63 & 30.79 & 46.67 & 28.54 & 27.68 & 68.53 & 42.79 & 34.64 & 72.61 \\
\hline & & $p$-value & 0.000 & 0.000 & 0.000 & 0.000 & 0.000 & 0.000 & 0.000 & 0.000 & 0.000 \\
\hline
\end{tabular}

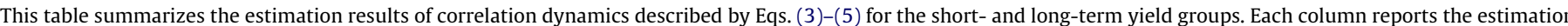

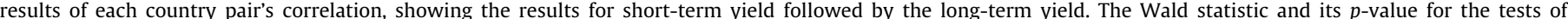

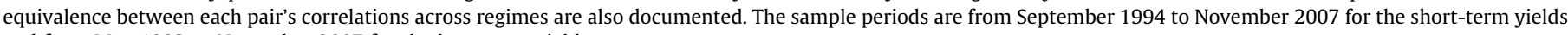
and from May 1993 to November 2007 for the long-term yields.
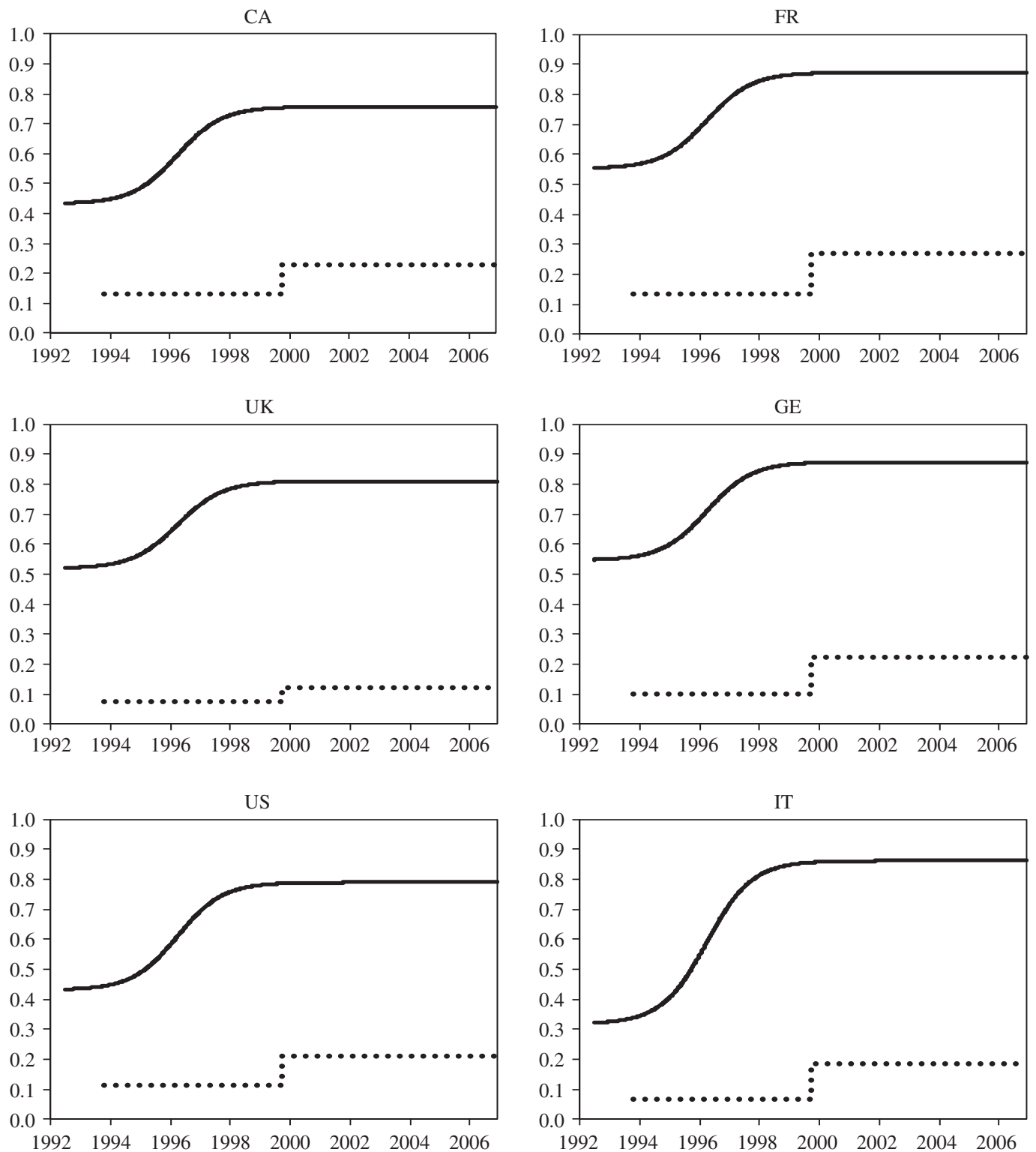

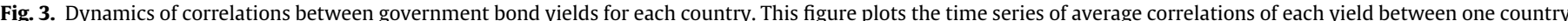

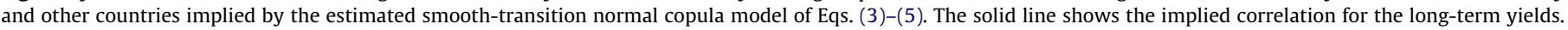
The dotted line shows the implied correlation for the short-term yields. 
three pairs, while correlations for the short yields stay nearly the same level for the CA-UK and UK-US pairs, although the CA-US pair's correlation between the short-term yields shares the same trend as that of the long-term yield. As a consequence, the difference in average correlations between the long- and short-term yields has increased from 0.365 to 0.625 during the sample period. These observations provide strong evidence relating to the first three questions stated above for ES countries.

The last three columns in Table 3 report the estimation results for the EZ countries based on the sample from September 1994 to November 2007. As can be seen from the table, the basic results are essentially the same or even more striking for EZ countries; correlations between the long-term yields have increased significantly for all pairs, while the short-term yield correlations for the FR-IT and GE-IT pairs show no significant change, although FR-GE pair has experienced significant increase in correlation between short-term yields. In addition, correlations between long-term yields are much higher than those for the short-term yields. Given the introduction of the Euro in January 1999, these results are more surprising than those for ES countries. We can also confirm these results as well as the correlation dynamics from Fig. 1. As can be seen from the figure, correlations between short-term yields (dotted line) for the FR-IT and GE-IT stay almost at the same level, and if anything decline slightly, although FR-GE show some increase. On the other hand, the long yields (solid line) experienced a very rapid increase in correlation between 1996 and 1998 for all pairs. This is in contrast to the results for ES countries, which suggest an almost linear increase in correlations between the long-term rates. Overall, our analysis indicates very similar tendency in the degree of, and changes in correlations between government bond yields for ES and EZ countries, but different dynamics in correlations between the long-term yields.

Using the estimation results for the ES and EZ country group, we can examine the possibility of decoupling between the short- and long-term yields. Table 4 reports the results of estimation and hypothesis tests of equivalence for correlations between shortand long-term yields across regimes for each country. The results are clear-cut, indicating a significant decrease in correlations for 4 out of 6 countries. We fail to reject the null of equivalence for correlations for CA and GE; for CA it is most likely due to the use of two-year yields as short-term yields instead of three-month yields; as a result, the correlation between the short- and longterm yields for CA is much higher than that for other countries with insignificant decrease across regimes. For GE, since the correlation between the short- and long-term yields is very small throughout the sample period, it is not unreasonable that we fail to reject the null in that case. These observations can also be confirmed from Fig. 2, which depicts the estimated correlation dynamics between the short- and long-term yields. In addition, Fig. 2 indicates that decoupling in ES countries happened almost linearly, whereas decoupling in EZ countries occurred mainly between 1996 and 1998. In summary, our results demonstrate the decoupling of the long-term yields from the short-term yields. This provides strong support of our basic premise: the evolution of interest rates of the short end of the curve continues to reflect primarily domestic monetary policy as well as domestic economic and financial market conditions, while at the long end of the curve, the importance of global conditions and global investor preferences have been paramount.

To provide further evidence of different characteristics in correlation dynamics between the short- and long-term yields, we also investigate the correlation dynamics across the different country groups. To this end, we estimate the joint model for two more groups based on the type of yields for each of the country pairs using the sample from September 1994 to November 2007 for the short-term yields and from May 1993 to November 2007 for the long-term yields. Table 5 summarizes the estimation and hypothesis test results for the short and long rates, respectively. Since we have already tested the equivalence of correlations within the ES and EZ countries, Table 5 reports the results only for the pairs across each country groups. As can be seen, the results are practically the same as those for within the ES and EZ countries. The significant increase in correlations between the long-term yields can be observed for all pairs, while the short-term yield correlations show no significant change at the $5 \%$ significance level for all pairs except the US-FR pair. In addition, correlations between long-term yields are much higher than those for the short-term yields. To provide a summary of the intertemporal evolution of these developments and confirm the points visually, Fig. 3 plots the time series of average correlations of the short-term yield (dotted line) and the long-term yield (solid line) between one country and other countries. For example, the dotted line in CA panel shows the average correlations between CA's short-term yield and that of other five countries, and so on. As can be seen from the figure, the conclusions are robust for all countries.

\section{Summary and policy implications}

Against the backdrop of the most serious global economic and financial crisis since the 1930s, this paper has tried to investigate the dynamics of cross-border government bond market integration in six of the largest G7 economies over almost two decades up to the onset of the crisis. The motivation is to see the extent to which one of the underlying causes of the crisis-that of the loss of traction of monetary policy in influencing long-term rates in the largest economies-is reflected in a decoupling of short- and long-term rates, and also to explore changes in the degree of international integration at the short and long end of the yield curve. We also investigate the dynamics of the evolution of integration. These issues are explored using the novel and rigorous smooth-transition copula-GARCH model that provides a convenient method to capture dominant long-run trends of correlations in bond yields. In addition, the copula framework allows us to model and estimate marginal and copula models separately, increasing tractability.

Our results show a clear weakening of the relationship between the short and long rates for most major industrial countries, with an almost monotonic decline over the last two decades in the case of the US and the UK. At the same time, there was a marked increase in the degree of international integration of long-term rates across most country groups.

Specifically, the estimation results for the ES country group indicate generally no significant increase in the pair-wise correlation between short-term government bond yields, but a highly significant increase with regard to the long-term yields with a much higher degree of correlation than that of short-term yields. Correlations for the long yields increased almost linearly for all three pairs, while correlations for the short yields stayed at nearly the same level for the CA-UK and UK-US pairs, although for the CAUS pair correlation between the short-term yields showed a similar trend as that of the long-term yield.

In the case of the EZ countries, the basic results are essentially the same or even more striking: correlations between the longterm yields have increased significantly for all pairs, while the short-term yield correlations for the FR-IT and GE-IT pairs show no significant change, although the FR-GE pair has experienced a marked increase in correlation between short-term yields. In addition, correlations between long-term yields are much higher than those for the short-term yields.

These results are consistent with the premise that the evolution of short rates reflected primarily domestic monetary policy and domestic economic and financial market conditions, while the long 
rates were increasingly determined by international investor preferences and global financial market conditions. They are thus compatible with the notion that monetary policy has begun to have much less traction in influencing long rates, which in turn was a contributing factor to the buildup of the asset price bubble in several of the major economies and the ensuing crisis. It is too early to surmise how the crisis will affect the correlations at the short and long end of the yield curve as they existed in mid- to late-2007. However, if fundamental factors that have been instrumental in leading to the outcome discussed in this paper begin to reassert themselves as the crisis wanes, the efficacy of traditional monetary policy will again be called into question, and the issue of diversification for this asset class within the largest economies will need to be reassessed.

\section{Acknowledgements}

We are indebted to James Hamilton and seminar participants at the Bank of Japan, Osaka University, Kobe University, Hitotsubashi University, University of Tokyo, and the Tokyo Finance Workshop for their valuable comments and suggestions. Work on this paper was begun when Manmohan Kumar was a Visiting Professor at McDonough School of Business, Georgetown University. Okimoto thanks the JSPS Postdoctoral Fellowships for Research Abroad and the Grant-in-Aid for Scientific Research for the financial support.

\section{References}

Abad, P., Chuliá, H., Gómez-Puig, M., 2010. EMU and European government bond market integration. Journal of Banking and Finance 34, 2851-2860.

Ahearne, G.A., Griever, W.L., Warnock, F.E., 2004. Information costs and home bias: An analysis of US holdings of foreign equities. Journal of International Economics 62 (2), 313-336.

Balli, F., 2009. Spillover effects on government bond yields in Euro zone. Does full financial integration exist in European government bond markets? Journal of Economics and Finance 33, 331-363.

Barr, D.G., Priestley, R., 2004. Expected returns, risk and the integration of international bond markets. Journal of International Money and Finance 23 (1), 71-97.

Bayoumi, T., Eichengreen, B., 1998. Exchange rate volatility and intervention: Implications of the theory of optimum currency areas. Journal of International Economics 45 (2), 191-209.

Beliu, S., 2005. International Financial Integration. Ph.D. Dissertation, Western Michigan University.

Berben, R.-P., Jansen, W.J., 2005. Comovement in international equity markets: A sectoral view. Journal of International Money and Finance 24, 832-857.

Breger, L., Stovel, D., 2005. Global integration of developed credit markets. Journal of Portfolio Management 31 (3), 60-69.

Cai, Y., Chou, R.Y., Li, D., 2009. Explaining international stock correlations with CPI fluctuations and market volatility. Journal of Banking and Finance 33, 20262035

Clarida, R., 2007. A Great Moderation, But Global Diversification is Still a Great Deal. PIMCO, January.

Click, R.W., Plummer, M.G., 2005. Stock market integration in ASEAN after the Asian financial crisis. Journal of Asian Economics 16 (1), 5-28.

Davies, A., 2007. International bond market cointegration using regime switching techniques. Journal of Fixed Income 16 (4), 69-80.

Duisenberg, W., 2002. The integration of Europe's financial markets. President of the European Central Bank, Speech at the 42nd Annual Meeting of the World Federation of Exchanges in Amsterdam, 8 October 2002.

Doyle, B.M., Faust, J., 2005. Breaks in variability and comovement of G7 economic growth. Review of Economic and Statistics 87 (4), 721-740.
Embrechts, P., McNeil, A., Straumann, D., 2002. Correlation and dependence properties in risk management: Properties and pitfalls. In: Dempster, M. (Ed.) Risk Management: Value at Risk and Beyond. Cambridge University Press, Cambridge, pp. 176-223.

European Commission, 2001, 2003. European Financial Integration Report, Brussels, Belgium.

Favero, C.A., Pagano, M., von Thadden, E-L., 2010. How does liquidity affect government bond yields? Journal of Financial and Quantitative Analysis 45 (1), 107-134.

Fidora, M., Fratzscher, M., Thimann, C., 2007. Home bias in global bond and equity markets: The role of real exchange rate volatility. Journal of Internationa Money and Finance 26 (4), 631-655.

Greenspan, A., 2007. The Age of Turbulence: Adventures in a New World. Penguin Press, New York.

Hardouvelis, G.A., Malliaropulos, D., Priestley, R., 2006. EMU and European stock market integration. Journal of Business 79 (1), 365-392.

Hauner, D., Kumar, M.S., 2006. Fiscal policy and interest rates: How sustainable is the new economy. Working Paper WP/06/112, International Monetary Fund.

Hauner, D., Kumar, M.S., 2009. Financial conditions and fiscal performance in emerging markets. Contemporary Economic Policy 27 (1), 86-96.

Hauner, D., Leigh, D., Skaarup, M., 2007. Ensuring fiscal sustainability in G7 economies. Working Paper WP/07/187, International Monetary Fund.

International Monetary Fund, 2009. World Economic Outlook, April.

Joe, H., 1997. Multivariate Models and Dependence Concepts. Chapman \& Hall London.

Jondeau, E., Rockinger, M., 2006. The copula-GARCH model of conditional dependencies: An international stock market application. Journal of International Money and Finance 25, 827-853.

Kim, S.-J., Moshirian, F., Wu, E., 2006. Evolution of international stock and bond market integration: Influence of the European Monetary Union. Journal of Banking and Finance 30 (5), 1507-1534.

Kose, M.A., Prasad, E., Rogoff, K., Wei, S.J., 2009. Financial globalization: A reappraisal. International Monetary Fund Staff Papers 56, pp. 8-62.

Kumar, M.S., Okimoto, T., 2007. Dynamics of persistence in international inflation rate. Journal of Money, Credit, and Banking 39 (6), 1457-1479.

Lamedica, N., Reno, R., 2007. Integration of international bond markets: Did anything change with EMU? Applied Economics Letters 14 (11), 829-832.

Lane, P.R., 2006. Global bond portfolios and EMU. International Journal of Central Banking 2 (2), 1-23.

Laopodis, N.T., 2003. International interest rate linkages: Implications for monetary policy. Managerial Finance 29 (11), 1-16.

Lin, C.-F.J., Teräsvirta, T., 1994. Testing the constancy of regression parameters against continuous structural change. Journal of Econometrics 62, 211-228.

Martens, M., Poon, S.-H., 2001. Returns synchronization and daily correlation dynamics between international stock markets. Journal of Banking and Finance 25, 1805-1827.

Nelsen, R.B., 2006. An Introduction to Copulas. Lecture Notes in Statistics, second ed. Springer, New York

Okimoto, T., 2008. New evidence of asymmetric dependence structures in international equity markets. Journal of Financial and Quantitative Analysis 43 (3), 787-816.

Panchenko, V., Wu, E., 2009. Time-varying market integration and stock and bond return concordance in emerging markets. Journal of Banking and Finance 33 1014-1021.

Patton, A., 2006a. Modelling asymmetric exchange rate dependence. International Economic Review 47 (2), 527-556.

Patton, A., 2006b. Estimation of multivariate models for time series of possibly different lengths. Journal of Applied Econometrics 21 (2), 147-173.

Poterba, J.M., 1989. Tax reform and the market for tax-exempt debt. Regional Science and Urban Economics 19 (3), 537-562.

Sklar, A., 1959. Fonctions de répartition à $n$ dimensionset leurs marges. Publications de l'Institut Statistique de l'Université de Paris 8, pp. 229-231.

Stock, J.H., Watson, M.K., 2005. Understanding changes in international business cycle dynamics. Journal of European Economic Association 3 (5), 968-1006.

Teräsvirta, T., 1994. Specification, estimation, and valuation of smooth transition autoregressive models. Journal of the American Statistical Association 89, 208218.

Tesar, L., Werner, I.M., 1995. Home bias and high turnover. Journal of International Money and Finance 14 (4), 467-492.

Yang, J., Zhou, Y., Wang, Z., 2009. The stock-bond correlation and macroeconomic conditions: One and a half centuries of evidence. Journal of Banking and Finance 33, 670-680. 